\title{
ANALYSIS OF PATIENTS WHO PRESENT TO EMERGENCY DEPARTMENTS DURING RAMADAN
}

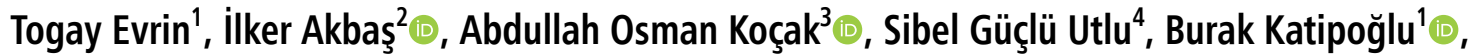 \\ Lukas Szarpak $^{5}$, Meryem Betos Koçak ${ }^{6}$, Zeynep Çakır ${ }^{3}$ \\ 'Department of Emergency Medicine, Faculty of Medicine, University of Ufuk, Ankara, Turkey \\ ${ }^{2}$ Department of Emergency Medicine, Bingöl State Hospital, Bingol, Turkey \\ ${ }^{3}$ Department of Emergency Medicine, Faculty of Medicine, University of Ataturk, Erzurum, Turkey \\ ${ }^{4}$ Department of Emergency Medicine, Erzurum Education and Research Hospital, Erzurum, Turkey \\ ${ }^{5}$ Lazarski University, Warsaw, Poland \\ ${ }^{6}$ Department of Family Medicine, University of Ataturk, Erzurum, Turkey
}

\begin{abstract}
INTRODUCTION: Fasting is one of the five basic obligations of Islam. Muslims fast during the month of Ramadan according to the lunar calendar. Fasting during Ramadan involves abstinence from food and drinks from sunrise to sunset. The present study investigated the effect of fasting during Ramadan in patients who presented to emergency departments. Results of this study may guide healthcare authorities in countries that provide health services to Muslim communities because of increased migration.
\end{abstract}

MATERIAL AND METHODS: This is the first prospective multicentre study to examine emergency department applications for Ramadan. The study was performed between 05.26.2017 and 06.24.2017. Patients were classified according to cardiopulmonary complaints, trauma-associated complaints, neurological complaints, gastrointestinal complaints, headache, renal colic, upper respiratory tract complaints, and malaise. Vital signs, age, gender, presentation type, complaint type, hospital stay duration, requested laboratory examination, radiological examination, treatment outcomes, application time, smoking status, and fasting status of the study patients were recorded by using a questionnaire.

RESULTS: Fasting and non-fasting patients showed a significant difference with respect to presentation type, gastrointestinal complaints, upper respiratory tract complaints, hospitalization status, requested radiological and biochemical examinations, hospitalization duration, and application time $(p<0.05)$.

CONCLUSIONS: To the authors' knowledge, the present study is the first to compare the complaints of fasting and non-fasting patients during Ramadan. The authors feel that this study is superior to several previous studies because it has been performed using a different perspective and provides more accurate and objective data than those reported in previous studies.

KEY WORDS: Ramadan, fasting, patient care, demographic analysis, emergency

Disaster Emerg Med J 2019; 4(2): 33-41

\section{INTRODUCTION}

Fasting is a type of devotion in which Muslims consciously abstain from consuming food and drinks for spiritual discipline and self-control. Fasting, which is one of the fundamentals of Islam, is performed from dawn (sahur) to sunset (iftar) during the month of

ADDRESS FOR CORRESPONDENCE:

Ilker Akbas, Emergency Physician, MD, Department of Emergency Medicine, Bingöl State Hospital, Bingöl Turkey;

E-mail: akbasilker@gmail.com, Cell phone: 00905444222880, Fax: 00904422363133

Address: Atatürk Üniversitesi, Tıp Fakültesi, Acil Tıp Anabilim Dalı, Yakutiye, Erzurum 
Ramadan according to the lunar calendar. In addition to abstaining from consuming food and drinks, Muslims avoid taking intravenous medication and intramuscular treatment during the fasting period. However, they can consume food and drinks from sunset to sunrise during this month [1].

Ramadan is the ninth month of the year according to the lunar calendar and includes 29 or 30 days depending on the year. According to the Gregorian calendar, the month of Ramadan begins 11 days earlier each year than the previous year because the lunar year is 11-days shorter than the solar year (354 days vs. 365 days). Therefore, the fasting period can last for 18 hours, especially during the summer months. The Islamic religion exempts patients with chronic illnesses, children, elderly individuals, psychiatric patients, healthy passengers, pregnant women, and nursing mothers from fasting $[2,3]$.

Prediction of the number of patients visiting emergency departments and characteristics of these patients is difficult and may vary according to seasons, local events, school terms, increase in the number of visitors from the outside city, or special periods such as Ramadan [2]. To maintain the quality of patient care, to ensure effective patient flow, and to decrease the length of hospital stay, it is important to maintain a balance between available healthcare resources and patient demand. Health administrators should closely follow changes in social dynamics and make preparations accordingly [2]. In communities with large Muslim populations, the month of Ramadan is associated with important changes in the presentation of patients to hospitals, especially emergency departments. This is because the eating habits of people, the amount of consumed food and liquid, duration and period of sleeping, and period of physical activity change considerably during Ramadan. These compulsory changes in the way of life associated with Ramadan exert inevitable effects on human metabolism. A long period of hunger and dehydration may cause some discomforts and may result in the remission of some illnesses [1]. The present study investigated the effect of fasting during Ramadan in patients presenting to emergency departments. Results of such studies may help healthcare authorities in Muslim countries, which are home to approximately one billion Muslim people, and other countries that have seen an increase in Muslim population because of the recent increase in migration but have less experience in providing improved healthcare services to this population [4].

\section{MATERIALS AND METHODS}

\section{Study design and setting}

This prospective multicentre study was performed at two centres in Turkey, namely, the emergency department of Atatürk University, a tertiary-care centre in the east of Turkey, i.e., in Erzurum province (hospital 1), and the emergency department of Private Ufuk University Hospital, which is located in the capital city of Turkey, i.e., in Ankara province (hospital 2).

\section{Patients}

This study was performed between the dates 05.26.2017 and 06.24.2017, which corresponded to the month of Ramadan in Turkey. Patients who presented to the emergency departments of both the hospitals during the specified period were included in the study. Patients who did not agree to participate in the study, who left the emergency departments without permission during treatment and follow-up periods, and who provided incomplete information in study forms were excluded from the study. Patients included in the study were grouped according to their complaints. Only one complaint per patient was accepted and was indicated as the most disturbing complaint. In the process of grouping complaints, the symptoms associated with each other were grouped under the same heading. Thus, the study patients were classified according to cardiopulmonary complaints (chest pain, dyspnea, and palpitations), trauma-related complaints (in-car traffic accident, traffic accident without a vehicle, minor trauma, fall, and assault), neurological complaints (syncope, side findings, speech disorder, dizziness, and seizure), gastrointestinal complaints (abdominal pain, nausea/vomiting, and diarrhoea), headache, renal colic, upper respiratory tract complaints, and fatigue. Patients who presented to the emergency departments with complaints besides the abovementioned complaints were not included in the study.

\section{Measurements}

All the patients included in the study completed study forms that were previously prescribed by physicians in the emergency departments. Vital signs (blood pressure, pulse rate, temperature, and oxygen saturation), age, sex, presentation type, complaint type, hospital stay duration, requested laboratory examination (whole blood count analysis, 
biochemical analysis, and urinalysis) and radiological examination (direct radiography, computed tomography $[\mathrm{CT}]$, ultrasonography [USG], and magnetic resonance imaging $[\mathrm{MRI}]$ ), treatment outcome (hospitalization and discharge), application time, smoking status, and fasting status were recorded. Presentation type included an outpatient presentation and ambulance presentation. The time (in minutes) between arrival to the hospital and treatment outcome was recorded as the duration of emergency department stay. The requested laboratory and radiological examinations were recorded as done or not done. Application time was determined by considering the beginning and end time of fasting. At hospital 1, the beginning time of fasting during Ramadan was between 02:44 and 02:54 hours and the end time of fasting was between 19:41 and 19:55 hours. At hospital 2, the beginning time of fasting during Ramadan was between 03:17 and 03:27 hours and the end time of fasting was between 20:15 and 20:29 hours. Application time was divided into six periods, namely, sahur (1:00-4:00 hours), dawn (4:00-8:00 hours), morning (08:00-12:00 hours), afternoon (12:0018:00 hours), iftar (18:00-21:00 hours), and night (21:00-01:00 hours).

\section{Statistical analysis}

Statistical analyses were performed using SPSS 20 statistical analysis program (IBM). Data were presented as mean, standard deviation, median, minimum, maximum, percentage, and number. Normal distribution of continuous variables was assessed using Shapiro-Wilk and Kolmogorov-Smirnov tests. Independent samples $t$-test was used for comparing normally distributed data between two independent groups, and the Mann-Whitney $U$ test was used to compare non-normally distributed data. Categorical variables were compared using Chi-square and Fisher's exact tests. A $p$ value of $<0.05$ was considered statistically significant.

\section{RESULTS}

This study included 2502 patients (1905 [76.1\%] patients from hospital 1 and 597 [23.9\%] patients from hospital 2). The proportion of male patients was $44.9 \%(n=1124)$. The age and vital signs of the patients are shown in Table 1.

In all, $23.1 \%(n=577)$ patients included in the study were smokers; moreover, $6.4 \%(n=159)$ patients presented to the emergency departments by using an ambulance. In all, 33.3\% ( $=833)$ patients requested for whole blood count analysis, $31.1 \%(n=778)$ patients requested for biochemical analysis, $9.7 \%(n=242)$ patients requested for urinalysis, $37.7 \%(n=943)$ patients requested for direct radiography, 9.8\% $(n=246)$ patients requested for $C T, 2.6 \%(n=66)$ patients requested for USG, and $1 \%(n=25)$ patients requested for MRI. Furthermore, 8.2\% ( $n=206)$ patients required hospitalization, while the remaining patients were discharged. The median stay of the patients at the emergency departments was 30 minutes (IQR1: 15 minutes, IQR3: 60 minutes, mean: 52.29 minutes, minimum: 5 minutes, maximum: $540 \mathrm{~min}-$ utes). In all, $46.7 \%(n=1169)$ patients who presented to the emergency departments during the month of Ramadan were fasting. Distribution of patients' complaints according to the fasting status of the patients is shown in Table 2 .

Among non-fasting patients, the number of women was significantly higher than that of men $(p=0.001)$. The incidence of gastrointestinal complaints was $26.9 \%$ among non-fasting patients and $18.7 \%$ among fasting patients. Moreover, there was observed a significantly higher number of fasting patients presented to the emergency departments with upper respiratory tract complaints than non-fasting patients $(21.8 \%$ vs. $14.7 \% ; p=0.000)$.

However, no significant differences were observed between fasting and non-fasting patients with respect to trauma-related complaints, neurological complaints, headache, side pain, and fatigue.

Table 1. Age and vital signs of the study patients
\begin{tabular}{|l|l|l|l|l|}
\hline & \multicolumn{1}{|c|}{ Median } & \multicolumn{1}{|c|}{ \pm SD } & \multicolumn{1}{c|}{ Minimum } & \multicolumn{1}{c|}{ Maximum } \\
\hline Age [year] & 41.09 & 18.1 & 18 & 97 \\
\hline Systolic blood pressure $[\mathrm{mm} \mathrm{Hg}]$ & 124.88 & 16.27 & 74 & 230 \\
\hline Diastolic blood pressure $[\mathrm{mm} \mathrm{Hg}]$ & 76.93 & 10.189 & 40 & 138 \\
\hline Temperature $\left[{ }^{\circ} \mathrm{C}\right]$ & 36.62 & 0.49 & 36 & 40 \\
\hline Oxygen saturation $[\%]$ & 95.21 & 3.52 & 54 & 100 \\
\hline Pulse rate [beats/min] & 83.99 & 11.99 & 40 & 164 \\
\hline
\end{tabular}




\begin{tabular}{|c|c|c|c|c|c|c|c|c|}
\hline & & \multicolumn{4}{|c|}{ Fasting Status } & & & \multirow[b]{3}{*}{$\mathrm{p}$} \\
\hline & & \multicolumn{2}{|c|}{ No } & \multicolumn{2}{|c|}{ Yes } & \multicolumn{2}{|c|}{ Total } & \\
\hline & & $\mathrm{n}$ & $\%$ & $\mathrm{n}$ & $\%$ & $\mathrm{n}$ & $\%$ & \\
\hline \multirow[t]{2}{*}{ Sex } & Female & 775 & $58.1 \%$ & 603 & $51.6 \%$ & 1378 & $55.1 \%$ & \multirow{2}{*}{$\begin{array}{l}x 2=10.822 \\
p=0.001\end{array}$} \\
\hline & Male & 558 & $41.9 \%$ & 566 & $48.4 \%$ & 1124 & $44.9 \%$ & \\
\hline \multirow[t]{2}{*}{ Presentation type } & Outpatient & 1235 & $92.6 \%$ & 1108 & $94.8 \%$ & 2343 & $93.6 \%$ & \multirow{2}{*}{$\begin{array}{l}x 2=4.765 \\
p=0.029\end{array}$} \\
\hline & Ambulance & 98 & $7.4 \%$ & 61 & $5.2 \%$ & 159 & $6.4 \%$ & \\
\hline \multirow[t]{2}{*}{ Trauma-related complaints } & No & 1097 & $82.3 \%$ & 954 & $81.6 \%$ & 2051 & $82.0 \%$ & \multirow{2}{*}{$\begin{array}{l}x 2=0.199 \\
p=0.655\end{array}$} \\
\hline & Yes & 236 & $17.7 \%$ & 215 & $18.4 \%$ & 451 & $18.0 \%$ & \\
\hline \multirow[t]{2}{*}{ Cardiopulmonary complaints } & No & 1179 & $88.4 \%$ & 1046 & $89.5 \%$ & 2225 & $88.9 \%$ & \multirow{2}{*}{$\begin{array}{l}x 2=0.673 \\
p=0.412\end{array}$} \\
\hline & Yes & 154 & $11.6 \%$ & 123 & $10.5 \%$ & 277 & $11.1 \%$ & \\
\hline \multirow[t]{2}{*}{ Neurological complaints } & No & 1261 & $94.6 \%$ & 1117 & $95.6 \%$ & 2378 & $95.0 \%$ & \multirow{2}{*}{$\begin{array}{l}x 2=1.201 \\
p=0.273\end{array}$} \\
\hline & Yes & 72 & $5.4 \%$ & 52 & $4.4 \%$ & 124 & $5.0 \%$ & \\
\hline \multirow[t]{2}{*}{ Gastrointestinal complaints } & No & 974 & $73.1 \%$ & 950 & $81.3 \%$ & 1924 & $76.9 \%$ & \multirow{2}{*}{$\begin{array}{l}x 2=23.651 \\
p=0.000\end{array}$} \\
\hline & Yes & 359 & $26.9 \%$ & 219 & $18.7 \%$ & 578 & $23.1 \%$ & \\
\hline \multirow[t]{2}{*}{ Headache } & No & 1219 & $91.4 \%$ & 1059 & $90.6 \%$ & 2278 & $91.0 \%$ & \multirow{2}{*}{$\begin{array}{l}x 2=0.562 \\
p=0.453\end{array}$} \\
\hline & Yes & 114 & $8.6 \%$ & 110 & $9.4 \%$ & 224 & $9.0 \%$ & \\
\hline \multirow[t]{2}{*}{ Upper respiratory tract complaints } & No & 1141 & $85.6 \%$ & 914 & $78.2 \%$ & 2055 & $82.1 \%$ & \multirow{2}{*}{$\begin{array}{l}x 2=23.304 \\
p=0.000\end{array}$} \\
\hline & Yes & 192 & $14.4 \%$ & 255 & $21.8 \%$ & 447 & $17.9 \%$ & \\
\hline \multirow[t]{2}{*}{ Abdominal or side pain } & No & 1267 & $95.0 \%$ & 1123 & $96.1 \%$ & 2390 & $95.5 \%$ & \multirow{2}{*}{$\begin{array}{l}x 2=1.504 \\
p=0.220\end{array}$} \\
\hline & Yes & 66 & $5.0 \%$ & 46 & $3.9 \%$ & 112 & $4.5 \%$ & \\
\hline \multirow[t]{2}{*}{ Malaise } & No & 1283 & $96.2 \%$ & 1125 & $96.2 \%$ & 2408 & $96.2 \%$ & \multirow{2}{*}{$\begin{array}{l}x 2=0.00 \\
p=0.986\end{array}$} \\
\hline & Yes & 50 & $3.8 \%$ & 44 & $3.8 \%$ & 94 & $3.8 \%$ & \\
\hline Complete blood count analysis & No & 811 & $60.8 \%$ & 858 & $73.4 \%$ & 1669 & $66.7 \%$ & $x 2=44.210$ \\
\hline & Yes & 522 & $39.2 \%$ & 311 & $26.6 \%$ & 833 & $33.3 \%$ & $p=0.000$ \\
\hline Biochemical analysis & No & 853 & $64.0 \%$ & 871 & $74.5 \%$ & 1724 & $68.9 \%$ & $x 2=32.152$ \\
\hline & Yes & 480 & $36.0 \%$ & 298 & $25.5 \%$ & 778 & $31.1 \%$ & $p=0.000$ \\
\hline Urinalysis & No & 1153 & $86.5 \%$ & 1107 & $94.7 \%$ & 2260 & $90.3 \%$ & $x 2=47.930$ \\
\hline & Yes & 180 & $13.5 \%$ & 62 & $5.3 \%$ & 242 & $9.7 \%$ & $p=0.000$ \\
\hline Direct radiography & No & 818 & $61.4 \%$ & 741 & $63.4 \%$ & 1559 & $62.3 \%$ & $x 2=1.084$ \\
\hline & Yes & 515 & $38.6 \%$ & 428 & $36.6 \%$ & 943 & $37.7 \%$ & $p=0.298$ \\
\hline Computed tomography & No & 1185 & $88.9 \%$ & 1071 & $91.6 \%$ & 2256 & $90.2 \%$ & $x 2=5.196$ \\
\hline & Yes & 148 & $11.1 \%$ & 98 & $8.4 \%$ & 246 & $9.8 \%$ & $p=0.023$ \\
\hline Ultrasonography & No & 1287 & $96.5 \%$ & 1149 & $98.3 \%$ & 2436 & $97.4 \%$ & $x 2=7.342$ \\
\hline & Yes & 46 & $3.5 \%$ & 20 & $1.7 \%$ & 66 & $2.6 \%$ & $p=0.007$ \\
\hline Magnetic resonance imaging & No & 1316 & $98.7 \%$ & 1161 & $99.3 \%$ & 2477 & $99.0 \%$ & $x 2=2.199$ \\
\hline & Yes & 17 & $1.3 \%$ & 8 & $0.7 \%$ & 25 & $1.0 \%$ & $p=0.138$ \\
\hline Hospitalization & Discharged & 1189 & $89.2 \%$ & 1107 & $94.7 \%$ & 2296 & $91.8 \%$ & $x 2=24.927$ \\
\hline & Hospitalized & 144 & $10.8 \%$ & 62 & $5.3 \%$ & 206 & $8.2 \%$ & $p=0.000$ \\
\hline
\end{tabular}

Significantly higher number of fasting patients requested for whole blood count analysis (39.2\% vs. $26.6 \%)$, biochemical analysis ( $36.5 \%$ vs. $25.5 \%)$, and urinalysis $(13.5 \%$ vs. $5.3 \%)$ than non-fasting patients $(p=0.000)$. In contrast, $11.1 \%$ non-fasting patients requested for $\mathrm{CT}$ compared with $8.4 \%$ fasting patients $(p=0.023)$. Moreover, a higher number of non-fasting patients requested for USG than 
fasting patients (3.5\% vs. $1.7 \% ; p=0.007$ ). However, no difference was observed between fasting and non-fasting patients with respect to the request for MRI and direct radiography. In all, 5.3\% $(n=206)$ fasting patients were hospitalized compared with $10.8 \%(n=144)$ non-fasting patients $(p=0.000)$.

Differences in the vital signs of fasting and non-fasting patients are shown in Table 3. It was observed that although the values of fever, systolic blood pressure, and oxygen saturation were significantly different between fasting and non-fasting patients $(p<0.001)$, the means of these values were not clinically significant between the two groups. Moreover, no significant difference was observed between fasting and non-fasting patients with respect to diastolic blood pressure and heart rate.

The median duration of hospital stay was 45 minutes (min. 5 minutes, max. 540 minutes) in non-fasting patients and 20 minutes (min. 5 minutes, max. 40 minutes) in fasting patients, which was significantly different $(p=0.000)$. Moreover, patients in the two groups showed a signifi- cant difference with respect to age $(p=0.002)$, with the median age of non-fasting patients being 37 years (min.18 years, max. 97 years) and that of fasting patients being 36 years (min.18 years, max.93 years).

Assessment of the time of presentation to the emergency departments indicated that 59.3\% of patients who presented between 08:00 and $12: 00$ hours and $63.9 \%$ of patients who presented between 12:00 and 18:00 hours did not fast. In contrast, $58.8 \%$ of patients who presented to the emergency departments between 21:00 and 01:00 hours fasted. These results indicate that the time of presentation to the emergency departments was significantly different between the fasting and non-fasting patients $(p=0.000)$. However, no significant difference was observed between fasting and non-fasting patients who presented to the emergency departments between 01:00 and 04:00, 04:00 and 08:00, and 18:00 and 21:00 hours. Distribution of the study patients according to the time of presentation to the emergency departments and fasting status is shown in Table 4.

\begin{tabular}{|c|c|c|c|c|}
\hline Variables & Fasting & $\mathrm{n}$ & Median \pm SD & p \\
\hline \multirow[t]{2}{*}{ Fever } & No & 1333 & $36.67 \pm 0.48$ & \multirow[t]{2}{*}{0.000} \\
\hline & Yes & 1169 & $36.56 \pm 0.49$ & \\
\hline \multirow[t]{2}{*}{ Systolic blood pressure } & No & 1333 & $123.91 \pm 17.15$ & \multirow[t]{2}{*}{0.001} \\
\hline & Yes & 1169 & $125.98 \pm 15.13$ & \\
\hline \multirow[t]{2}{*}{ Diastolic blood pressure } & No & 1333 & $76.63 \pm 10.42$ & \multirow[t]{2}{*}{0.119} \\
\hline & Yes & 1169 & $77.27 \pm 9.91$ & \\
\hline \multirow[t]{2}{*}{ Pulse rate } & No & 1333 & $84.08 \pm 13.11$ & \multirow[t]{2}{*}{0.675} \\
\hline & Yes & 1169 & $83.88 \pm 10.59$ & \\
\hline \multirow[t]{2}{*}{ Oxygen saturation } & No & 1333 & $95.38 \pm 3.65$ & \multirow[t]{2}{*}{0.010} \\
\hline & Yes & 1169 & $95.01 \pm 3.36$ & \\
\hline
\end{tabular}

Table 4. Effect of fasting status on the time of presentation to the emergency departments
\begin{tabular}{|l|c|c|c|}
\hline & \multicolumn{2}{|c|}{ Fasting status } \\
\hline \multicolumn{1}{|c|}{ Time period } & No $(\mathrm{n}[\%])$ & Yes $(\mathrm{n}[\%])$ & Total $(\mathrm{n}[\%])$ \\
\hline 01:00-04:00 hours & $61(49.6 \%)$ & $62(50.4 \%)$ & $123(100 \%)$ \\
\hline 04:00-08:00 hours & $57(56.4 \%)$ & $44(43.6 \%)$ & $381(100 \%)$ \\
\hline 08:00-12:00 hours & $229(59.3 \%)$ & $157(40.7 \%)$ & $723(100 \%)$ \\
\hline 12:00-18:00 hours & $462(63.9 \%)$ & $261(36.1 \%)$ & $387(100 \%)$ \\
\hline 18:00-21:00 hours & $202(52.2 \%)$ & $185(47.8 \%)$ & $782(100 \%)$ \\
\hline 21:00-01:00 hours & $322(41.2 \%)$ & $460(58.8 \%)$ & $2502(100 \%)$ \\
\hline Total & $1333(53.3 \%)$ & $1169(46.7 \%)$ & \\
\hline
\end{tabular}




\section{DISCUSSION}

This is the first prospective multicentre study to examine patients presenting to emergency departments according to their fasting status during Ramadan, which indicates the uniqueness of this study. Although many studies have reviewed patients presenting to emergency departments during Ramadan, these studies have been retrospective in nature. Moreover, these studies did not assess the fasting status of patients presenting to emergency departments. The presented study assessed the fasting status and emergency services required by patients during Ramadan more accurately and objectively than previous studies $[1,2,4-7]$.

One study assessed 40000 Muslim subjects, of which 93\% fasted during Ramadan [8, 9]. In Turkey, $99 \%$ of the population is Muslim, of which $66 \%$ are estimated to fast during Ramadan. [7]. The present study is the first to assess the fasting rate of patients presenting to emergency departments. These results do not overlap those of the above survey. In the present study, $46.7 \%(n=1169)$ patients presenting to emergency departments fasted during Ramadan. This difference may be due to the fact that the patients with chronic illnesses are exempted from fasting according to the Islamic religion. Although the rate of fasting is high in Muslim communities. But the rate of fasting is lower in patients who admitted emergency departments than the normal population. This study clearly reported the complaints of the fasting population during Ramadan.

Most previous studies have assessed the effects of fasting during Ramadan on the general health of the fasting population. Nevertheless, the number of studies that have not examined the relationship between the month of Ramadan and the number of applications is very small [6]. A previous study reported patients presented to emergency departments during Ramadan because of the following complaints: upper respiratory tract infection (24\%); acute gastroenteritis (17\%); abdominal pain (9\%); skin infection, kidney infection, renal colic (6\%); and resting (3\%) [10]. Fasting, circadian rhythm changes, and improper treatment commonly result in gastroduodenal ulcers and complications [10].

Measurement of vital signs is the easiest method to assess the effects of the onset of hunger on metabolism. Hussain et al. reported that fasting during Ramadan was associated with a decrease in heart rate, which was caused by a decrease in catecholamine production [11]. Although the heart rate of fasting patients was lower than that of non-fasting patients $(83.88 \pm 10.59$ beats $/ \mathrm{min}$ and $84.08 \pm 13.11$ beats/min, respectively) in the present study, the difference was not statistically significant $(p>0.05)$. However, the present study reported a statistically significant difference in systolic blood pressure, fever, and finger-tip oxygen saturation values between fasting and non-fasting patients $(p<0.001)$. this difference, However, was not clinically significant because these parameters were within the expected normal range. Therefore, these findings indicate that fasting does not alter the meaning of the vital findings.

Results of studies assessing the relationship between fasting and cardiopulmonary complaints are highly controversial. Some studies have shown that fasting exerts protective effects on the cardiovascular system and that there is no difference in the requirement of emergency services for cardiac complaints between Ramadan and non-Ramadan months [1, 4, 6, 12-16]. However, few studies have provided contradictory results. These studies indicate that the incidence of acute coronary syndromes is higher during Ramadan than in the other months, especially among people with advanced age and with hypertension $[14,17]$. However, the present study could not establish an association between fasting and the incidence of cardiopulmonary complaints.

Trauma-related complaints were not different between fasting and non-fasting patients, which is inconsistent with that reported in previous related studies. Some studies have shown that the number of pounding and assault incidents and car accidents decrease during Ramadan because of a decrease in alcohol consumption [10, 12, 18]. In contrast, Bener et al. showed that more people were injured in traffic accidents during Ramadan than in the other months [19]. Langford et al. [20] investigated traffic accidents during Ramadan and did not report a statistically significant increase in the number of casualties in the Muslim population due to traffic accidents during Ramadan.

The present study did not show any association between fasting and incidence of neurological complaints, which is consistent with that reported in previous studies. Results of previous studies suggest that hunger does not play a role in triggering neurological diseases and that changes in eating habit, diurnal rhythm, and sleep regimen are not risk factors of neurological diseases $[1,6,12,21,22]$. 
Hunger, however, directly affects the gastrointestinal system. Therefore, it is not surprising that the number of patients presenting to emergency departments with gastrointestinal complaints increases during Ramadan. Hunger-associated gastrointestinal complaints are caused by an increase in gastric acid levels [4, 23-25]. Increased gastric acid levels increase abdominal pain and may lead to peptic ulcer. Many studies have reported an increased incidence of these illnesses during the month of Ramadan compared with that during the other months $[4,12$, $23,26]$. However, there is no difference in the incidence of cholecystopathies such as acute cholecystitis, which are not directly associated with gastric acid levels [27]. In this regard, the results of the present study are different from those of previous studies. In the present study, the incidence of gastrointestinal complaints was lower in fasting patients (18.7\%) than in non-fasting patients $(26.9 \%)(p<0.001)$. Peptic ulcer and its related complications were the most common gastrointestinal complaints in previous studies. In the present study, all the patients with gastrointestinal complaints were classified as having peptic ulcers. Generally, fasting exerts a protective effect against gastrointestinal complaints. It is believed that gastrointestinal complaints reported in the present study may be related to the resting of the gastrointestinal organs and to hunger.

Hunger alone is considered to be the cause of headache. In addition, lifestyle changes such as deterioration of sleep and decreased caffeine and tobacco intake during Ramadan are suggested to cause headaches [1, 7, 28-30]. However, some studies have not established any association between fasting during Ramadan and the incidence of headaches. Al Assaad et al. compared the incidence of headaches during Ramadan and non-Ramadan months and observed no difference [1]. In the present study, no statistically significant difference was observed in the incidence of headaches between fasting and non-fasting patients. This may be due to the fact that Muslims choose a spiritual way of life during Ramadan by trying to stay away from emotional grief and by adopting a sedative lifestyle by decreasing the duration and intensity of daily physical activity.

Fluid and dietary restrictions during Ramadan can trigger biochemical factors related to stone formation. Liquid loss and dehydration caused by sweating in hot air reduce urine volume and increase urine density. This may result in the formation of renal stones. Therefore, the incidence of renal colic is expected to be higher during Ramadan than during the other months. However, the association between the incidence of renal colic and fasting during Ramadan has not been clearly established. Although many studies have suggested an association between the incidence of renal colic and fasting during Ramadan, many other studies have provided an opposite view [1, 4, 31-35]. The present study did not report a statistically significant difference in the incidence of renal colic between fasting and non-fasting patients. This may be because fasting patients were not dehydrated and their need for liquids was met between iftar and sahur hours.

In the present study, upper respiratory tract infection was the most common cause of presentation to the emergency departments. In all, 21.8\% fasting patients presented with an upper respiratory tract infection compared with $14.4 \%$ non-fasting patients, which was significantly different $(p<0.001)$. This may be because of the restriction of fluid intake and increased susceptibility of mucous membranes to dryness and infection. Consistently, previous studies have shown that the incidence of upper respiratory tract infections increases during Ramadan [10]. To the authors' knowledge, the present study is the first to assess the incidence of fatigue in fasting and non-fasting patients during Ramadan and did not report any significant difference in the incidence of fatigue between these two patients groups.

In addition to comparing the incidence of different health-related complaints between fasting and non-fasting patients, the present study compared the length of hospital stay, time of presentation to the emergency departments, and required physical and radiological examinations between fasting and non-fasting patients to ensure the maintenance of the quality of health services offered to Muslim communities during Ramadan. The average duration of hospital stay was 45 minutes (min. 5 minutes, max. 540 minutes) among non-fasting patients and 20 minutes (min. 5 minutes, max. 40 minutes) among fasting patients $(p=0.000)$. This difference may be because fasting patients may refuse to receive intravenous medication or treatment for intrinsic cirrhosis because of the concern that this may break their fast and therefore leave the emergency department quickly.

Assessment of the time of presentation to emergency departments during Ramadan indicates an increased number of patients presented to the 
emergency departments at night. A study conducted during Ramadan showed most patients presented to emergency departments between 20:00 and 23:00 hours [4]. In another study, $40 \%$ of patients presented to emergency departments between 23:00 and 8:00 hours [10]. Butt et al. showed that during Ramadan, approximately $60 \%$ of patients were presented to emergency departments during the night [2]. Another study reported most patients presented to emergency departments between 16:00 and 20:00 hours [6]. Only one related study assessed patients admitted to a cardiology clinic according to their fasting status and presentation time at the clinic during Ramadan. Results of this study showed that the fasting status of patients was not significantly associated with the time of presentation to the cardiology clinic. The present study showed that fasting patients were more likely to present to the emergency departments at night hours than during day and evening hours. In this case, the fasting population can be explained by referring to the hospital when there is no fasting. Next, the patient outcomes were investigated in the present study. It was observed that the hospitalization rate was $10.8 \%$ in fasting patients compared with $5.3 \%$ in non-fasting patients $(p<0.001)$. This difference indicates that patients with a serious illness are less likely to fast and that $10.8 \%$ of fasting patients continue to fast despite their illness.

In the present study, $7.4 \%$ non-fasting patients and $5.2 \%$ fasting patients were brought to the emergency departments by an ambulance $(p<0.01$ ). It is explained with the view that the non-fasting group uses more ambulances because the fasting population constitutes of individuals who have chronic diseases that prevent them from fasting. Patients with chronic illnesses are critical and need to be transported to hospitals by an ambulance. The present study is the first to assess diagnostic tests requested by patients who presented to emergency departments during Ramadan. It was observed that more of the fasting patients requested for complete blood count analysis, biochemical analysis, urinalysis, CT, and USG than the non-fasting patients. This may be because non-fasting patients may include an increased number of patients with chronic illnesses.

During Ramadan, Muslims abstain from using recreational items such as cigarettes in addition to abstaining from consuming food and drinks. Therefore, in the present study, the association between fasting and smoking habit was examined and no signifi- cant difference in smoking habit between fasting and non-fasting patients was observed. This finding indicates that smokers prefer to perform religious duties rather than smoke during the month of Ramadan.

\section{CONCLUSION}

Fasting during Ramadan may be associated with changes in some but not all disease states. The results of the present study have added substantial new information to the existing literature on this topic. This study provides important information on gastrointestinal and upper respiratory tract infections, length of hospital stay, and time of presentation to emergency departments of fasting and non-fasting patients during Ramadan. Moreover, the present study is the first to assess diagnostic tests requested by and cigarette use by fasting and non-fasting patients during Ramadan.

Acknowledgements: There are no acknowledgements for the manuscript

Conflict of interest: The authors have no conflict of interest to declare

\section{REFERENCES}

1. Assaad RAl, Bachir R, Sayed MEl. Impact of Ramadan on emergency department visits and on medical emergencies. Eur J Emerg Med. 2017: 1, doi: 10.1097/mej.0000000000000485.

2. Butt T, Khan HU, Ahmed I, et al. Emergency department attendance patterns during Ramadan. Ann Saudi Med. 2016; 36(4): 258-264, doi: 10.5144/0256-4947.2016.258, indexed in Pubmed: 27478911.

3. Beano AM, Zmaili MA, Gheith ZH, et al. Predetermined Anti-Diabetic Drug Regimen Adjustments during Ramadan Fasting: An Observational Study of Safety. Endocrinol Metab (Seoul). 2017; 32(2): 265-273, doi: 10.3803/EnM.2017.32.2.265, indexed in Pubmed: 28685515.

4. Balhara KS, Levin S, Cole G, et al. Emergency department resource utilization during Ramadan: distinct and reproducible patterns over a 4-year period in Abu Dhabi. Eur J Emerg Med. 2018; 25(1): 39-45, doi: 10.1097/MEJ.0000000000000405, indexed in Pubmed: 27101280.

5. Mehmood A, Khan IQ, Mir MU, et al. Vulnerable road users are at greater risk during Ramadan - results from road traffic surveillance data. J Pak Med Assoc. 2015; 65(3): 287-291, indexed in Pubmed: 25933563.

6. Pekdemir $M$, Ersel $M$, Yilmaz $S$, et al. No significant alteration in admissions to emergency departments during Ramadan. J Emerg Med. 2010; 38(2): 253-256, doi: 10.1016/j.jemermed.2008.03.013, indexed in Pubmed: 18842386.

7. Topacoglu H, Karcioglu O, Yuruktumen A, et al. Impact of Ramadan on demographics and frequencies of disease-related visits in the 
emergency department. Int J Clin Pract. 2005; 59(8): 900-905, doi: 10.1111/j.1742-1241.2005.00460.x, indexed in Pubmed: 16033610.

8. Lugo L, Cooperman A, Bell J, et al. The 's Muslims: Unity an rld's Muslims: Unity and Diversity. World. 2012.

9. Miller T. Mapping the global Muslim population: a report on the size and distribution of the world's Muslim population. Washington, DC: Pew Research Center. 2009.

10. Halasa W. Effect of Ramadan fasting on emergency walk-in-clinics in Jordan. Br J Gen Pract. 2014; 64(625): 388, doi: 10.3399/bjgp14X680833, indexed in Pubmed: 25071034.

11. Husain R, Duncan MT, Cheah SH, et al. Effects of fasting in Ramadan on tropical Asiatic Moslems. Br J Nutr. 1987; 58(1): 41-48, indexed in Pubmed: 3620437.

12. Göçmen $E$, Koç $M$, Tez $M$, et al. Effect of Ramadan on surgical emergencies. Ann Emerg Med. 2004; 44(3): 283-285, indexed in Pubmed: 15332311.

13. Temizhan A, Dönderici O, Ouz D, et al. Is there any effect of Ramadan fasting on acute coronary heart disease events? Int J Cardiol. 1999; 70(2): 149-153, indexed in Pubmed: 10454303.

14. Mustafa K, Mahmoud N, Gumno K, et al. The effect of fasting in Ramadan: serum uric acid lipid concentration. Br J Nutr. 1978; 40: 573-581.

15. Al Suwaidi J, Zubaid M, Al-Mahmeed WA, et al. Impact of fasting in Ramadan in patients with cardiac disease. Saudi Med J. 2005; 26(10): 1579-1583, indexed in Pubmed: 16228059.

16. Al Suwaidi J, Bener A, Gehani AA, et al. Does the circadian pattern for acute cardiac events presentation vary with fasting? J Postgrad Med. 2006; 52(1): 30-33.

17. Sriha Belguith $A$, Baccouche $H, G$ rissa $M H$, et al. The risk of acute coronary syndrome in Ramadan. Tunis Med. 2016; 94(8-9): 599-603, indexed in Pubmed: 28685795.

18. Göçmen $E$, Koç $M$, Tez $M$, et al. Effect of Ramadan on surgical emergencies. Ann Emerg Med. 2004; 44(3): 283-285, indexed in Pubmed: 15332311.

19. Bener A, Absood GH, Achan NV, et al. Road traffic injuries in Al-Ain City, United Arab Emirates. J R Soc Health. 1992; 112(6): 273-276, indexed in Pubmed: 1469673.

20. Langford EJ, Ishaque MA, Fothergill J, et al. The effect of the fast of Ramadan on accident and emergency attendances. J R Soc Med. 1994; 87(9): 517-518, indexed in Pubmed: 7932456.

21. Bener $A$, Hamad $A$, Fares $A$, et al. Is there any effect of Ramadan fasting on stroke incidence? Singapore Med J. 2006; 47(5): 404-408, indexed in Pubmed: 16645691.

22. Akhan G, Kutluhan S, Koyuncuoglu HR. Is there any change of stroke incidence during Ramadan? Acta Neurol Scand. 2000; 101(4): 259-261, indexed in Pubmed: 10770523.
23. Ozkan S, Durukan $P, A k d u r ~ O$, et al. Does Ramadan fasting increase acute upper gastrointestinal haemorrhage? J Int Med Res. 2009; 37(6): 1988-1993, doi: 10.1177/147323000903700637, indexed in Pubmed: 20146899.

24. Iraki L, Abkari A, Vallot T, et al. Effect of Ramadan fasting on intragastric $\mathrm{pH}$ recorded during 24 hours in healthy subjects. Gastroenterol Clin Biol. 1997; 21(11): 813-819, indexed in Pubmed: 9587531.

25. Hakkou F, Tazi A, Iraqui $L$, et al. The observance of Ramadan and its repercussion on gastric secretion. Gastroenterol Clin Biol. 1994; 18(3): 190-194, indexed in Pubmed: 7926431.

26. Dönderici 0, Temizhan $A$, Küçükbaş T, et al. Effect of Ramadan on peptic ulcer complications. Scand J Gastroenterol. 1994; 29(7): 603-606, indexed in Pubmed: 7939395.

27. Hosseini SV, Torabijahromi M, Mosallaei M, et al. The effect of season and Ramadan fasting on the onset of acute cholecystitis. Saudi Med J. 2006; 27(4): 503-506, indexed in Pubmed: 16598328.

28. Drescher M, Wimpfheimer Z, Khalef $S A$, et al. Prophylactic Etoricoxib Is Effective in Preventing "First of Ramadan" Headache: A Placebo-Controlled Double-Blind and Randomized Trial of Prophylactic Etoricoxib for Ritual Fasting Headache. Headache: The Journal of Head and Face Pain. 2011; 52(4): 573-581, doi: 10.1111/j.1526-4610.2011.01993.x.

29. Mosek $A$, Korczyn AD. Fasting headache, weight loss, and dehydration. Headache. 1999; 39(3): 225-227, doi: 10.1046/j.15264610.1999.3903225.x, indexed in Pubmed: 15613218.

30. Torelli P, Evangelista A, Bini $A$, et al. Fasting headache: a review of the literature and new hypotheses. Headache. 2009; 49(5): 744-752, indexed in Pubmed: 19472450.

31. Abdolreza N, Omalbanin A, Mahdieh TS, et al. Comparison of the number of patients admitted with renal colic during various stages of peri-Ramadan month. Saudi J Kidney Dis Transpl. 2011; 22(6): 1199-1202, indexed in Pubmed: 22089781.

32. Cevik Y, Corbacioglu SK, Cikrikci G, et al. The effects of Ramadan fasting on the number of renal colic visits to the emergency department. Pak J Med Sci. 2016; 32(1): 18-21, doi: 10.12669/pjms.321.8248, indexed in Pubmed: 27022337.

33. al-Hadramy MS. Seasonal variations of urinary stone colic in Arabia. J Pak Med Assoc. 1997; 47(11): 281-284, indexed in Pubmed: 9510632.

34. Basiri A, Moghaddam SM, Khoddam R, et al. Monthly variations of urinary stone colic in Iran and its relationship to the fasting month of Ramadan. J Pak Med Assoc. 2004; 54(1): 6-8, indexed in Pubmed: 15058633.

35. Miladipour AH, Shakhssalim N, Parvin M, et al. Effect of Ramadan fasting on urinary risk factors for calculus formation. Iran J Kidney Dis. 2012; 6(1): 33-38, indexed in Pubmed: 22218117. 